\title{
Species composition dynamics in successive plant assemblages on the northern slopes of the coal mining spoils in the arid areas of Khakassia
}

\author{
Olga Safronova ${ }^{1}$, Tatiana Lamanova ${ }^{2}$, Natalia Sheremet, ${ }^{2, *}$, and Vladimir Doronkin ${ }^{2}$ \\ ${ }^{1}$ Research Institute of Agricultural Problems of Khakassia, 655132 Abakan, Russia \\ ${ }^{2}$ Central Siberian Botanical Garden of SB RAS, 630090 Novosibirsk. Russia
}

\begin{abstract}
The results of the study of the species composition dynamics in successive plant communities developing on the northern slopes of the coal mining spoils dating back to the $70 \mathrm{~s}, 80 \mathrm{~s}, 90 \mathrm{~s}$ and $2000 \mathrm{~s}$ years in the arid areas of Khakassia, are presented for the first time. During the first 10-15 years of revegetation there was an increase in taxonomic diversity in the successive plant assemblages. Endemic species of the Fabaceae family, common for the bunch grasses steppes and stony steppes of Khakassia, were not found on the northern spoil slopes. Mesoxerophytes were the most abundant ecological group. Drastic increase in the complexity of the successive plant assemblages in the arid areas of Khakassia was found to take place after 25-30 years of revegetation.
\end{abstract}

\section{Introduction}

Due to the surface coal mining huge areas become severely disturbed by such technogenic impact. Decreasing the negative effect is possible by restoring vegetation cover and biological productivity of the disturbed territories. Development of plant cover during revegetation of the coal mining soils has been receiving much attention of researchers in many countries $[1,2,3,4]$.

Coal mines in Khakassia are located along the routes of inverse aerial mass movement, bringing with them into the Chernogorsk and Abakan hollows, as well as other areas, plenty of dust from the explosive surface openings. In winter time with few winds all the industrial emissions stay above the densely populated cities and towns, slowly falling to the surface and hence negatively affecting human health. Plant cover that develops during revegetation of the spoils somewhat mitigates such negative effects.

The aim of the research was to study floristic composition of plant assemblages developed due to the revegetation succession on the coal mining spoils.

\footnotetext{
*Corresponding author: nsheremet@yandex.ru
} 


\section{Methods and environmental conditions}

The objects of the study were ecosystems located on the northern slopes (with the most favourable conditions) of the coal mining spoils formed by the Chernogorsk mine (LLC "SYEK-Khakassia") in the 70s, 80s, 90s and 2000s years, i.e. at 10 years increment, in the process of open mining.

Since 2008-2011 aboveground plant parts of different species were clipped to assess aboveground phytomass of a species and determine species composition of the economically significant botanical groups growing on the spoils. To study the vertical structure of aboveground phytomass the standing parts were cut down to the roots, then cut in 0-3, 10-20 and 20-30 cm layers and weighed as fresh mass [5]. Geobotanical description of the plant assemblages was carried out according to A.G. Voronov [6]. Projective plant cover (percentage) was assessed visually, while species abundance was determined according to the Drude scale. The phytocenosis type was determined according to the set of dominating species. Belowground phytomass storage and its vertical layer distribution was done by sampling soil monoliths in triplicates from the surface area of $10 \mathrm{dm} 3$ and $0-10$ and 10-20 cm layers only, as sampling from the deeper layers was not feasible. Roots were washed in water, then dried and weighed.

The climate of the region is sharply continental with cold long winters and hot dry summers. Average yearly temperature ranges +1.8 to $-1.0{ }^{\circ} \mathrm{C}$. The absolute temperature minimum occurs in January $\left(-40.6{ }^{\circ} \mathrm{C}\right)$, while the average maximum occurs in June $+35.6{ }^{0} \mathrm{C}$.

According to the geobotanical zoning by Kuminova et al. [7], the area of the Chernogorsk coal mining spoils can be regarded as part of the Near-Abakan (Central Khakassia) district of the Minusinsk hollow, where the most typical are the bunch grass and true steppes in a typical version of four-grasses steppe, distinguished by V.V. Reverdatto.

\section{Results and discussion}

Floristic composition of plant assemblages on the northern slopes of the technogenic chronosequence of coal mining spoils was found to consist of 40 species of higher vascular plants, representing 35 genera and 18 families. The most species-rich families were Asteraceae and Poaceae, accounting for $30 \%$ and $22.5 \%$, respectively. Prevalence of these families is indicative of the steppe type of vegetation succession.

The number of species representing the Fabaceae family is the highest among other families comprising the flora of the undisturbed regional bunch grass [7] and stony steppes of Khakassia. It is related to the fact that Minusinsk-Khakssia steppes since the end of Pleiocene have been the centre of the autochtonous development of legumes, which is confirmed by significant endemism of the regional flora [9]. However, endemic species, representing Fabaceae family, were not found on the studied coal mining spoils even after 40 years of revegetation.

Among multi-species genera found in stony and small tussock steppe were Astragalus, Oxytropis, Artemisia and Potentilla. According to L.I. Malyshev [10], increasing floristic importance of these genera is most likely due to the continental climate and montane relief.

On the northern slopes of the coal mining spoil chronosequence these multi-species genera were represented by two genera, namely Artemisia with 5 species and Cirsium with 2 species.

The number of plant species, families and genera were found to increase significantly over the first 20 years of the spoil revegetation (Tab.). 
Table. Dynamics of the species composition of plant assemblages developed on the northern slopes of the coal mining spoils in the arid area of Khakassia

\begin{tabular}{|c|c|c|c|c|}
\hline \multirow{2}{*}{ Floristic composition } & \multicolumn{4}{|c|}{ The time of spoil formation } \\
\cline { 2 - 5 } & $2000 \mathrm{~s}$ & $90 \mathrm{~s}$ & $80 \mathrm{~s}$ & $70 \mathrm{~s}$ \\
\hline Families & 5 & 12 & 12 & 14 \\
\hline Genera & 9 & 24 & 21 & 29 \\
\hline Species & 9 & 29 & 24 & 34 \\
\hline
\end{tabular}

All the observed species belonged to three ecological groups: the most represented were mesoxerophytes, contributing $41-46 \%$ into the standing aboveground phytomass, the second largest group were xerophytes, contributing 21-33\%, followed by mesophytes with their $22-28 \%$. In the stony steppes of Khakassia xerophytes account for $22 \%$ of the total number of species, while mesoxerophytes contribute $34 \%$; in the flora of bunch grass steppes xerophytes and mesophytes account for $49 \%$ of the total number of plant species.

Species richness can be considered as an indicator of a better or worse ecosystem status. Theoretically there is a transition from the geometric range via log-range and log-normal distribution towards the "broken shaft" model. Such transition follows increasing complexity of communities. Geometric range can be observed in case of very few species dominance with very low abundance of the others (hypothesis of niche conquest). The logrange and log-normal distribution are common for communities where species with average numbers become relatively more abundant and widely distributed (niches are multidimensional). The "broken shaft" model represents a situation, when species are distributed with maximally possible evenness (and hyper-capacity niche bounds are located randomly) [11, 12].

During revegetation of the northern slopes of the coal mining spoils open plant assemblage gradually had become more structurally complex: in the 2000 s described by a geometric range, and in the following decades by a log-range and log-normal distribution. The model of "broken shaft" was found only once during the last year of observations on the spoils established in the 1990s (Fig.).

Therefore species composition of the plant assemblages developing during revegetation of the northern slopes of the coal mining spoils, i.e. in the habitats with the most favourable (in the arid zone)the slopes which in the arid zone conditions for plant growth and development, forms during the first 10-15 years of spoil revegetation.

All the species identified on the spoils belonged to three ecological groups: xerophytes, mesoxerophytes and mesophytes, with mesoxerophytes being most represented.

In contrast to the flora of stony and small tussock steppes of Khakassia, where endemic species represent Fabaceae family and Astragalus and Oxytropis genera, the latter were not found even after 40 years of coal mining spoils revegetation.

Gradual increase in the structure complexity of the open plant assemblages from the geometric range to the log-range and log-normal distribution was revealed. The "broken shaft" model was found only once during the last year of observations on the spoils dating back to the 1990s. In general all indicators evidenced that the structure of the studied plant assemblages was more or less developed/formed.

The study was financially supported by the Russian Foundation of Basic Research Grant 18-44190006 r_a. 

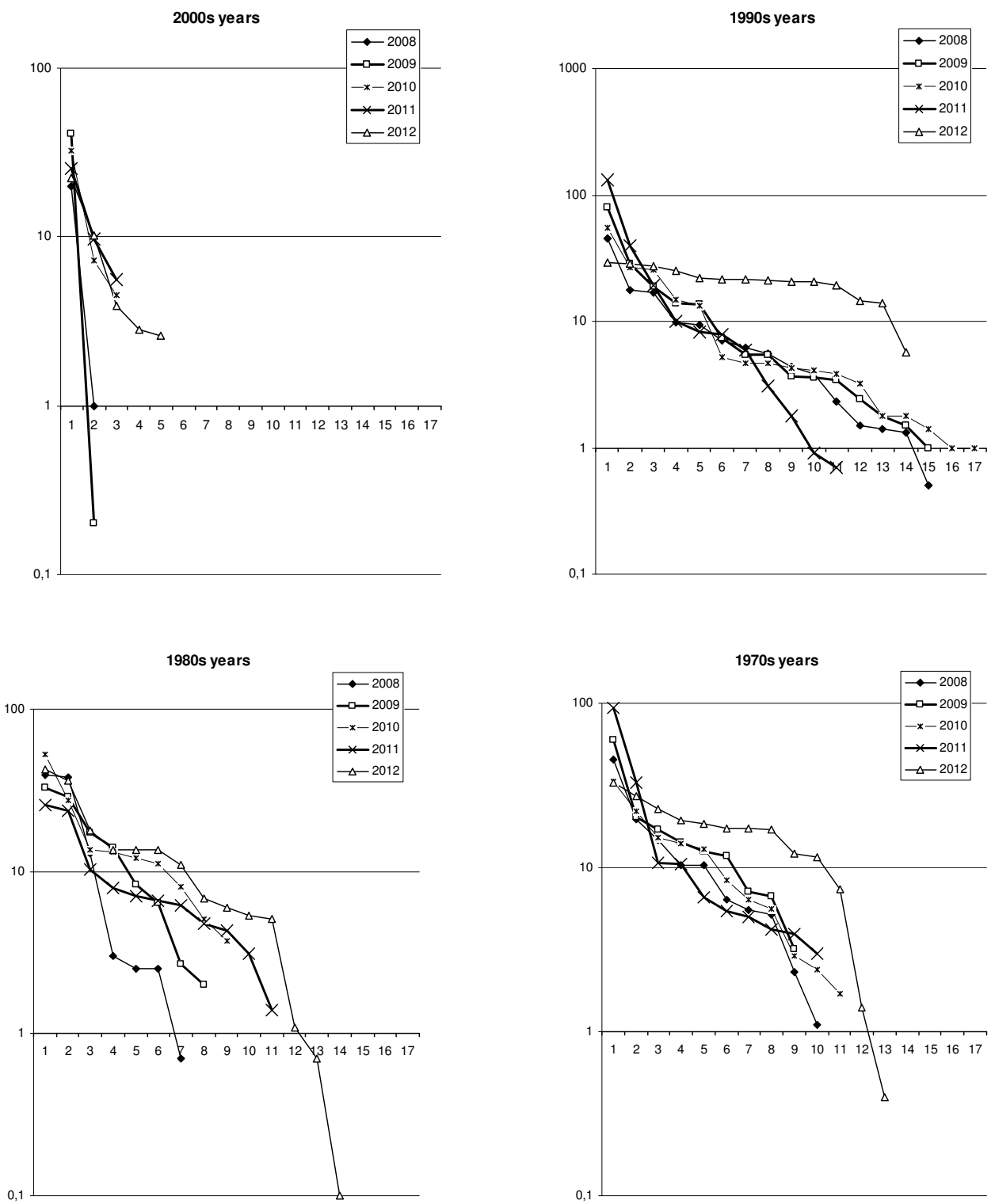

Figure. Significance curves for successive plant communities under natural revegetation of the northern slopes of the coal mining spoils in the arid areas of Khakassia.

$\mathrm{Y}$ axis represents species relative significances (vascular plants species air-dry phytomass, $\mathrm{g} / \mathrm{m}^{2}$ ).

$\mathrm{X}$ axis represents species ranks in descending order of abundances.

\section{References}

1. M. Hendrychová, J Landscape Studies 1, 1 (2008)

2. R. Tropek, T. Kadlec, M. Hejda, P. Kocarek, J. Skuhrovec, I. Malenovsky, S. Vodka, L. Spitzer, P. Banar, M. Konvicka, Ecol. Eng. 43, 1 (2012)

3. J. Banaszek, M. Leksy, O. Rahmonov, DOI: 10.3846/enviro.2017.098. (2017) 
4. H. Lei, Zh. Peng, H. Yigang, Zh. Yang, Ecol. Eng. 94 (2016)

5. A.A. Korchagin, E.M. Lavrenko, Field Geobotany (USSR AS Pbs., Moscow-St.Petersburg, 1976) in Russian

6. A.G. Voronov, Geobotany (Higher School, Moscow, 1973) in Russia

7. A.V. Kuminova, Y.M. Maskaev, G.A. Zvereva, Vegetation cover of Khakassia (Nauka Pbs., Novosibirsk, 1976) in Russian

8. T.G. Lamanova, in Geobotanical studies in West and Middle Siberia (Nauka Pbs., Novosibirsk, 1978) in Russian

9. A.V. Polozhy, Proc. SB USSR AS 4, 1 (1964) in Russian

10. L.I. Malyshev, The history of flora and vegetation in Eurasia (Nauka Pbs., Novosibirsk, 1972) in Russian

11. R.H. Whittaker, Communities and ecosistems (MacMillan Pbs., NY., 1975)

12. E. Megarran, Ecological Diversity and Its Measurement. (Mir Pbs., Moscow, 1992) 